\title{
Directions in Atom Probe Tomography
}

David Larson ${ }^{1}$, Dan Lenz ${ }^{2}$, Isabelle Martin ${ }^{2}$, Ty Prosa ${ }^{3}$, David Reinhard ${ }^{1}$, Peter Clifton ${ }^{4}$, Brian Geiser ${ }^{5}$, Robert Ulfig $^{1}$ and Joe Bunton ${ }^{2}$

${ }^{1}$ CAMECA Instruments Inc., Madison, Wisconsin, United States, ${ }^{2}$ CAMECA $®$ Instruments Inc., 5470 Nobel Drive, Madison, WI 53711 USA, United States, ${ }^{3}$ CAMECA $®$ Instruments Inc., 5470 Nobel Drive, Madison, WI 53711 USA, Wisconsin, United States, ${ }^{4}$ Cameca, United States, ${ }^{5}$ CAMECA Instruments Inc., United States

Peer reviewed manuscripts that include research using atom probe tomography (APT) [1] have increased at an amazing pace $(\sim 5 X)$ since about 2005 [2]. Such research relies on continued advances in the areas of hardware and software related to APT. The following topics: laser wavelength [3], advanced reconstruction algorithms [4], automated data acquisition and analysis [5], cryo/vacuum transfer [6], mass resolving power (MRP) - field of view tradeoffs (FOV) [7-9], and multi-direction laser incidence [10] are all areas in which CAMECA is working in order to promote enhanced APT data quality. The latter two are the focus of the current abstract. Historically, it has been highly desirable for an atom probe to have a combination of high MRP with a wide FOV in order to deliver excellent analytical capability over extended length scales. However, these two metrics are inherently at odds with each other, from a design perspective, due to (amongst other things) the high spread in flight-time variations (different flight paths) across the FOV of a large detector. Some efforts to overcome this difficulty employ reflectron energy compensating based solutions [8] while others use a straight flight path design [7,9]. This work presents our efforts to utilize novel patented technology [9], Fig. 1a, to produce an increased FOV in the atom probe, Fig. 1b, while maintaining very good MRP. As it is known that exposure to a single focused-laser-beam may lead to a non-hemispherical (asymmetrical) tip shape (especially when very high laser energy is utilized [11]), we are currently testing a system to irradiate an atom probe specimen from two sides in a thermally coincident manner. A comparison of a representative specimen shape (silicon) from one-beam and two-beam laser conditions is shown in Fig. 2ab. Making use of an algorithm designed to fit a high-order polynomial equation to each point across the surface of a specimen [12], the radii for each of the specimens are quantified in Fig. 2c. The average radii are $(77 \pm 18) \mathrm{nm}$ (one sigma) and $(56 \pm 2.6) \mathrm{nm}$ for the one- and two-beam conditions respectively (single points in center of Fig. $2 \mathrm{c}$ ), showing a decrease of $\sim 5 \mathrm{X}$ in the standard deviation as a percentage of the mean. 

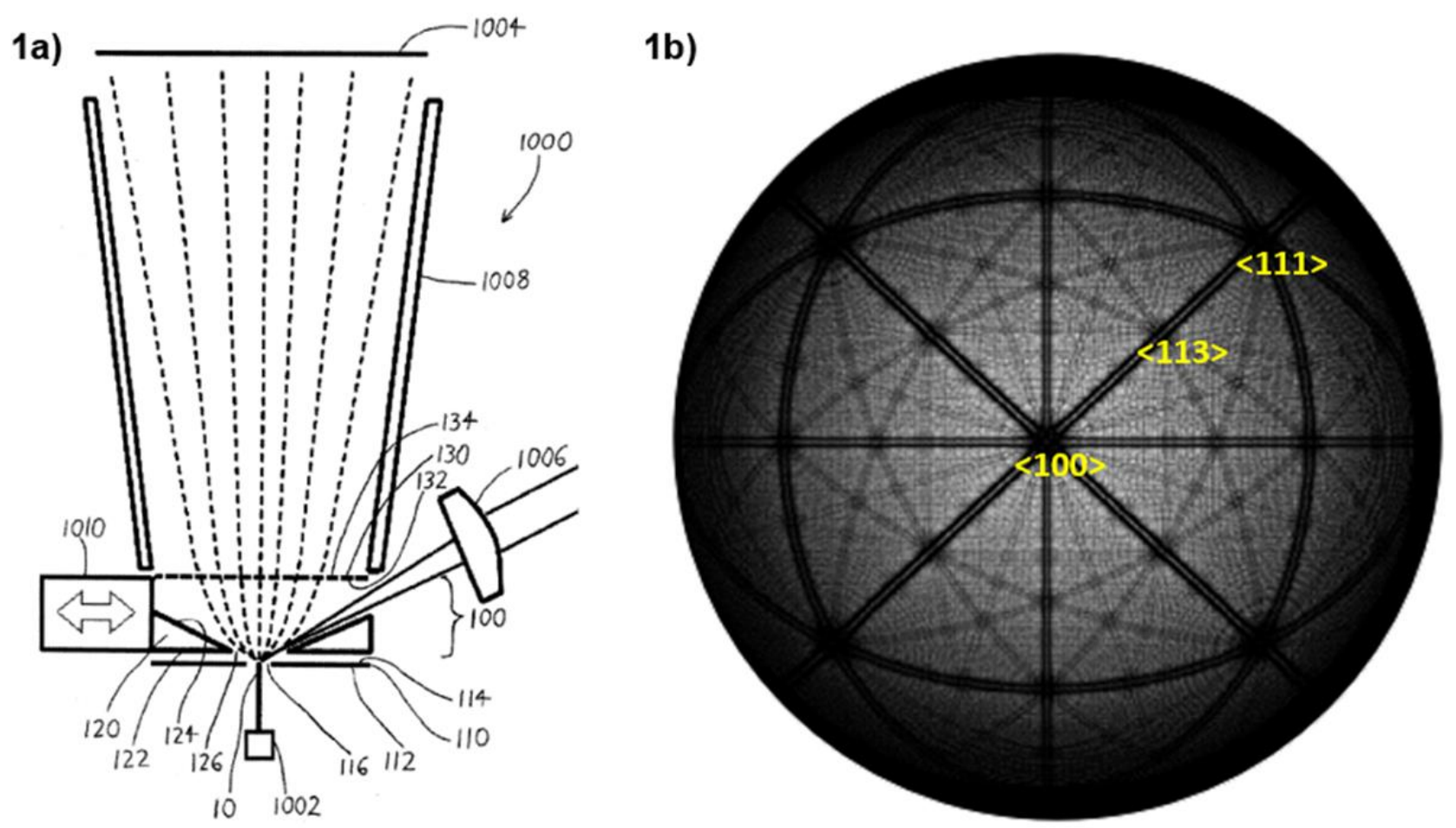

Figure 1. Figure 1. (a) Schematic design of a straight flight path atom probe (where the numbers are from specific designations within reference [8]) and (b) simulated field of view obtained by such a design (FCC crystal lattice with evaporation field $=30 \mathrm{~V} / \mathrm{nm}$ ).
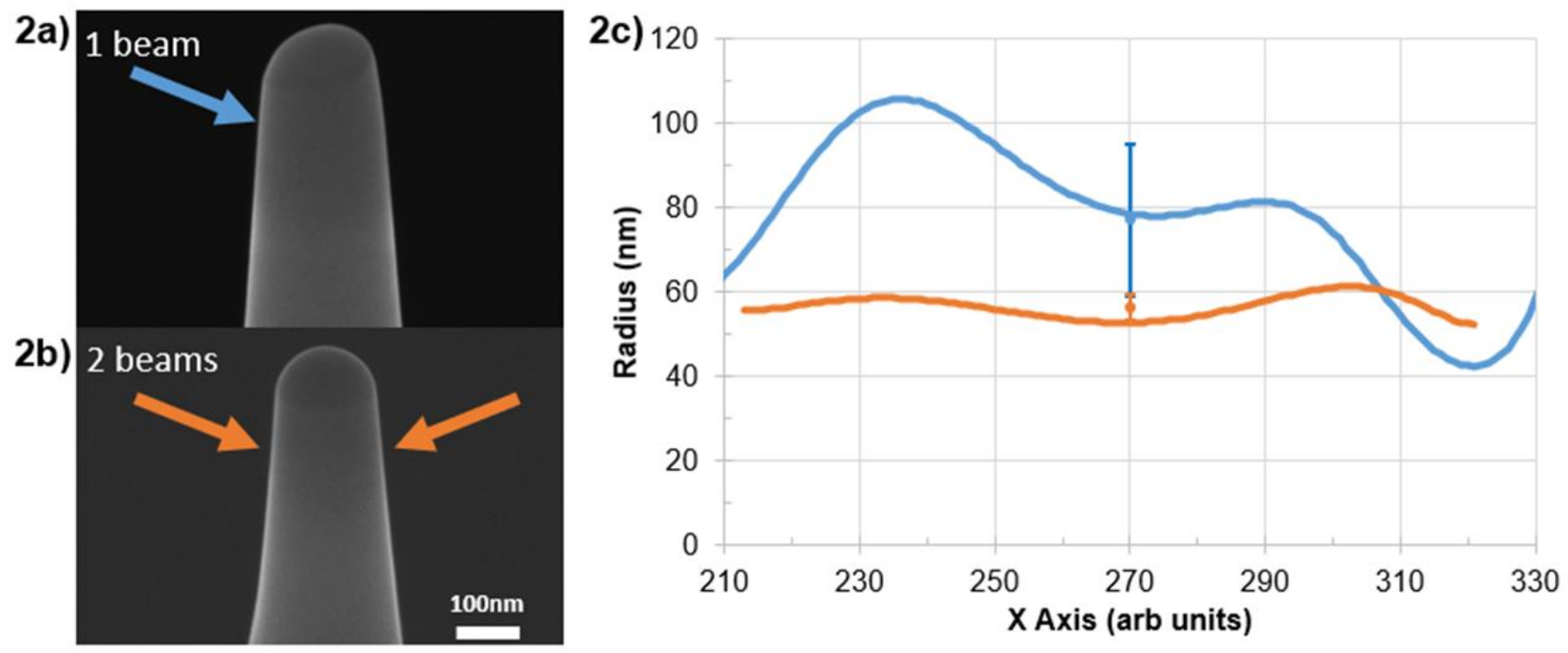
Figure 2. Figure 2. Si field evaporation endforms for (a) one-beam and (b) two-beam laser irradiation conditions. (c) shows quantification of the radii with the $\mathrm{x}$ axis in (c) corresponding to the $\mathrm{x}$ direction in (a) and (b).

\section{References}

[1] D. J. Larson et al., "Local Electrode Atom Probe Tomography: A User's Guide”, (Springer Scientific, New York, 2013).

[2] “LEAP 5000: 3D Atom Probe Microscope". https://www.cameca.com/products/apt/leap-5000 (accessed January 24, 2021).

[3] A. Chiaramonti et al., Micro. Microanal. 26(S2) (2020) 258.

[4] B. P. Geiser et al, Micro. Microanal. 26(S2) (2020) 2622.

[5] D. Reinhard, et al., Micro. Microanal. 26(S2) (2020) 2616.

[6[ R. M. Ulfig et al., Micro. Microanal. 23(S1) (2017) 622.

[7] A. Bostel et al, "High Resolution Wide Angle Tomographic Probe", United States Patent 8,074,292, December 6, 2011.

[8] P. Panayi, "Reflectron”, United States Patent 8,134,119, March 13, 2012.

[9] J. H. Bunton and M. S. Van Dyke, "Wide Field of View Atom Probe", United States Patent 10,615,001, April 7, 2020.

[10] T. F. Kelly et al., Surface Science246 (1991) 396.

[11] A. Shariq et al, Ultramicroscopy 109 (2009) 472.

[12] S. S. A. Gerstl et al., Micro, Microanal, 15(S2) (2009) 248. 